\title{
A prognostic profile of hypoxia-induced genes for localised high-grade soft tissue sarcoma
}

\author{
Ninna Aggerholm-Pedersen ${ }^{\star}, 1$, Brita Singers Sørensen ${ }^{1}$, Jens Overgaard ${ }^{1}$, Kasper Toustrup ${ }^{2}$, Steen Baerentzen ${ }^{3}$, \\ Ole Steen Nielsen ${ }^{4}$, Katja Maretty-Kongstad ${ }^{1}$, Marianne Nordsmark ${ }^{2}$, Jan Alsner ${ }^{1}$ and Akmal Safwat ${ }^{2}$ \\ ${ }^{1}$ Department of Experimental Clinical Oncology, Aarhus University Hospital, Norrebrogade 44, Aarhus C 8000, Denmark; \\ ${ }^{2}$ Department of Oncology, Aarhus University Hospital, Norrebrogade 44, Aarhus C 8000, Denmark; ${ }^{3}$ Department of Pathology, \\ Aarhus University Hospital, Norrebrogade 44, Aarhus C 8000, Denmark and ${ }^{4}$ Faculty of Health, Aarhus University, Nordre \\ Ringgade 1, Aarhus C 8000, Denmark
}

Background: For decades, tumour hypoxia has been pursued as a cancer treatment target. However, prognostic and predictive biomarkers are essential for the use of this target in the clinic. This study investigates the prognostic value of a hypoxia-induced gene profile in localised soft tissue sarcoma (STS).

Methods: The hypoxia-induced gene quantification was performed by real-time quantitative PCR (RT-qPCR) of formalin-fixed, paraffin-embedded tissue samples. The gene expression cut-points were determined in a test cohort of 55 STS patients and used to allocate each patient into a more or a less hypoxic group. The cut-points found in the test cohort were applied to a cohort of 77 STS patients for validation.

Results: For patients with localised high-grade STS treated with surgery with or without postoperative radiation therapy, the prognostic value of the hypoxia-induced gene profile was proved in the test cohort and confirmed in the validation cohort. After adjustment for confounders, the hazard ratio (HR) was $3.2(95 \% \mathrm{Cl}: 1.5 ; 7.0)$ for patients with more hypoxic tumours compared with patients with less hypoxic tumours regarding disease-specific survival. Moreover, for the development of metastatic disease, the HR was 2.61 (95\% Cl: 1.27; 5.33).

Conclusions: The hypoxia-induced gene profile is a validated independent prognostic marker that may help identify STS patients needing more aggressive or different adjuvant treatment.

About a quarter of patients with primary localised soft tissue sarcoma (STS) die within the first 5 years of being diagnosed (Maretty-Nielsen et al, 2014). Risk stratification is difficult and adjuvant treatment is toxic and has low efficacy. Novel prognostic and predictive markers are needed to make informed decisions and guide individualised treatment (Hunter et al, 2016).

Hypoxia is an adverse prognostic factor in different malignancies (Hockel et al, 1996; Evans et al, 2001; Evans and Koch, 2003; Nordsmark et al, 2005; Busk and Horsman, 2013) and its role in sarcoma has recently been explored (Kim et al, 2015). There is experimental evidence implicating hypoxia in increasing metastatic potential and dissemination of sarcomas (Eisinger-Mathason et al, 2013; Kim et al, 2013; El-Naggar et al, 2015). Traditionally, the Eppendorf needle electrode has been used for measuring tumour hypoxia. These measurements have shown that the level of pretreatment tumour oxygenation is a prognostic marker for disease-specific survival in STS patients (Nordsmark et al, 2001), and that preoperative low tumour $\mathrm{pO}_{2}$ could be an indicator of aggressive disease (Brizel et al, 1996). However, the Eppendorf method is invasive and requires special equipment and expertise.

${ }^{\star}$ Correspondence: Dr N Aggerholm-Pedersen; E-mail: ninnpe@rm.dk.

Received 3 June 2016; revised 22 August 2016; accepted 5 September 2016; published online 4 October 2016

(c) 2016 Cancer Research UK. All rights reserved 0007-0920/16 
An alternative way to determine tumour hypoxia is to monitor the expression of certain hypoxia-induced genes, whose change in expression is important for cellular adaptation to an anaerobic environment. This is a non-invasive and rapid method to reveal the presence of hypoxia in STS viable tumour tissue. If the hypoxiainduce gene profile is of prognostic value, it may help stratify patients for treatment either with more aggressive modalities or with hypoxia-targeting drugs.

The hypoxia-induced gene profile investigated in this paper was developed as a predictive marker for hypoxic modification of radiotherapy in head and neck cancer (Toustrup et al, 2012) and includes genes that are upregulated by hypoxia in a $\mathrm{pH}$-independent manner (Sorensen et al, 2010).

The aim of the present study was to investigate the prognostic role of this hypoxia-induced gene profile in STS patients.

\section{MATERIALS AND METHODS}

Patient cohorts. The study was performed on a test cohort of 55 patients and validated in an independent cohort of 77 patients.

The test cohort was built around the original material of 42 STS patients investigated by Nordsmark et al (2001 and by Bentzen et al (2003) in which hypoxia was measured using Eppendorf method between 1993 and 2001. Four patients were excluded because of benign histology and 8 patients because ofto lack of available tissue samples. The remaining 30 patients were matched $1: 2$ to the Aarhus Sarcoma Registry (ASR), a recently validated comprehensive clinical population-based database (MarettyNielsen et al, 2013).

The matching was done based on histological type, age at diagnosis, sex, and year of diagnosis. Exact match was not possible, but the cases that were 'best possible matches', according to the above-mentioned order of criteria, were manually selected. Inclusion was restricted to high-grade, localised STS with stored formalin-fixed, paraffin-embedded (FFPE) tissue samples taken before any treatment and with sufficient tissue for high-quality mRNA analysis. This resulted in a test cohort of 55 patients. For inclusion and exclusion criteria, see Figure 1.
The validation cohort was chosen among all patients treated with curatively intended surgery and postoperative radiation therapy for localised STS between 1998 and 2008. Patients without pretreatment FFPE tissue samples, as well as tissue samples with insufficient mRNA quality were excluded. This resulted in a cohort of 77 patients. Power calculation for the validation cohort was based on an expected hazard ratio (HR) of 2.0 between the more hypoxic and the less hypoxic patient groups. Based on this calculation, 66 patients were needed to detect this difference with $80 \%$ power.

The median follow-up time was 5.5 years $(0.2-23.8)$ and for patients still alive the median follow-up time was 8.2 years (4.4-23.8).

Tissue samples and preparation. FFPE tissue samples taken at the time of biopsy or surgery were used for investigation of the hypoxia-induced genes. These tissue samples represented different histological types: undifferentiated pleomorphic sarcoma (UPS; $n=51)$, liposarcoma $(n=28)$, leiomyosarcoma $(n=16)$, synovial sarcoma $(n=14)$, malignant peripheral nerve sheath tumour $(n=8)$, fibrosarcoma $(n=7)$, extra osseous osteosarcoma $(n=3)$, rhabdomyosarcoma $(n=3)$, and extra-osseous Ewing/PNET $(n=2)$. Information about time from tissue collection to fixation and fixation times was not available. Samples were excluded if haematoxylin and eosin (HE) staining showed either $>90 \%$ necrotic or $100 \%$ normal tissue. A specialised sarcoma pathologist reviewed all HE staining for estimation of the degree of necrosis.

Total RNA was extracted from $7-\mu \mathrm{m}$ whole FFPE tissue sections by the Tissue Preparation System with VERSANT Tissue Preparation Reagents (Siemens Healthcare Diagnostics, Tarrytown, NY, USA), a fully automated, bead-based RNA isolation method as described elsewhere (Bohmann et al, 2009). DNase I treatment was applied to remove any potential genomic DNA before cDNA preparation. Purified mRNA from FFPE tissue samples is known to be highly degraded and the mRNA quantity was therefore not determined. Yet, to perform RT-qPCR on the partly degraded RNA, short amplicons and pre-amplification steps were used as described and validated previously (Toustrup et al, 2011; Soes et al, 2013).

Primers and RT-qRCR. The cDNA preparation was performed using the high-capacity cDNA Archive kit (Applied Biosystems, Foster City, CA, USA) according to the manufacturer's protocol.

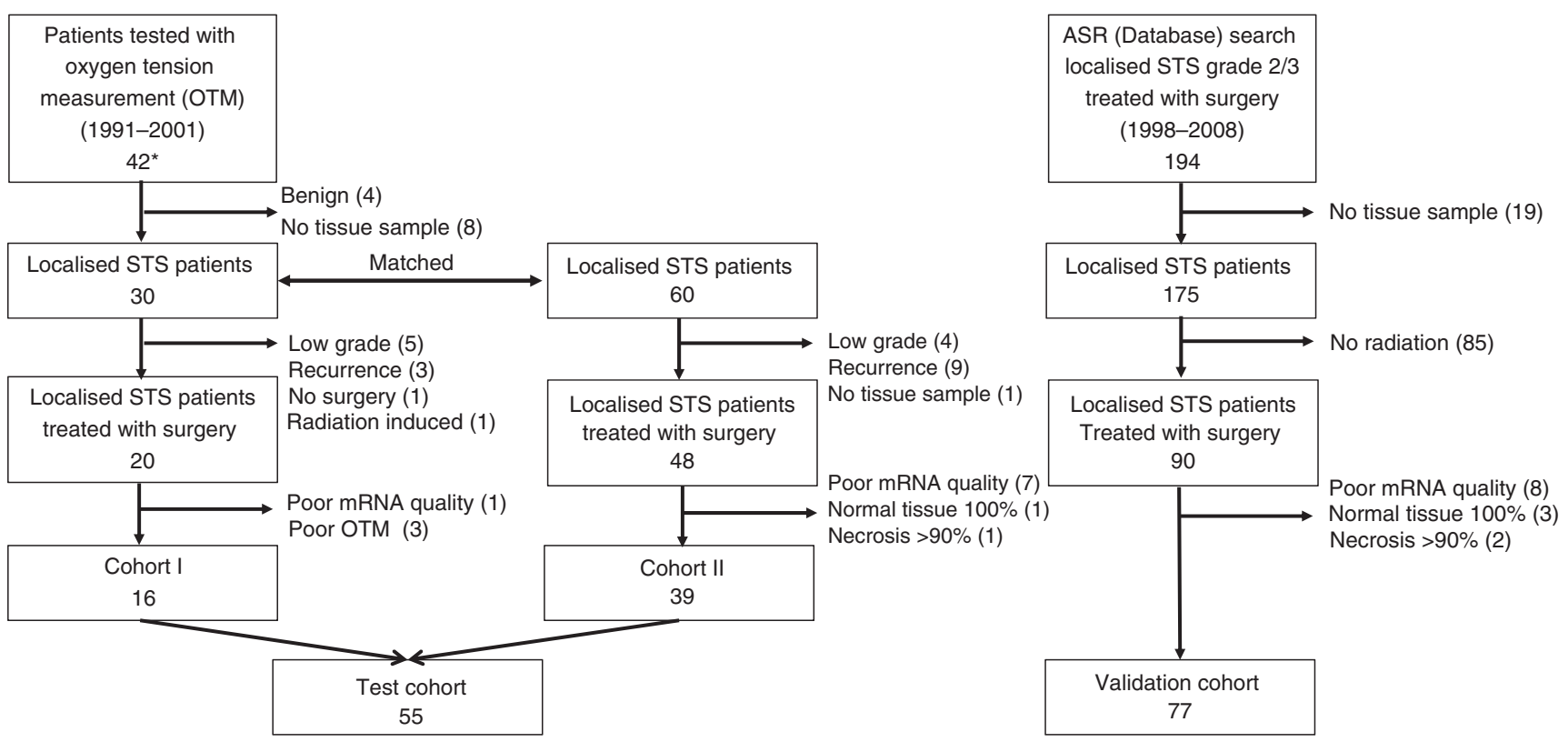

Figure 1. Diagram of patient selection of test and validation cohort. ARS = Aarhus sarcoma registry; OTM=oxygen tension measurement; STS = soft tissue sarcoma. *Nordsmark et al. British Journal of Cancer, 2001 and Bentzen et al. Radiotherapy and Oncology, 2003. 
First 10 cycles of pre-amplification were completed with few modification of the manufacturer's protocol (Taqman Preamp Master Mix, Applied Biosystems) as described elsewhere (Soes et al, 2013). The reference genes originally selected for the gene profile were chosen because of the high-correlation coefficient ( $\rho=0.98, P<0.001)$ between these genes and the 3 most stable reference genes previously tested among 22 well-known reference genes in 22 sarcoma patients representing part of the test (Aggerholm-Pedersen et al, 2014). All genes included in the analysis were upregulated by hypoxia in different tumour models and comprised a hypoxia-induced gene profile developed as a predictive factor in head and neck cancer (see Supplementary Table I, for genes and assay identification; Toustrup et al, 2012), patent no. WO/2012/146259. Assays were selected with an exon junction spanning probe when available. RT-qPCR was performed on an ABI PRISM 7900HT (Applied Biosystem) in 384-well plates by a Biomek 3000 (Beckman Coulter Inc., Brea, CA, USA). The final mixtures consisted of $3 \mu \mathrm{l}$ pre-amplified cDNA plus $2 \times$ TaqMan Genotyping Master Mix (Applied Biosystems) and $1 \times$ TaqMan assay including primers and probes at a final volume of $15 \mu \mathrm{l}$. The experiment was initiated by one cycle at $95^{\circ} \mathrm{C}$ for $10 \mathrm{~min}$, followed by 40 cycles of $95^{\circ} \mathrm{C}$ for $15 \mathrm{~s}$, and $60^{\circ} \mathrm{C}$ for $1 \mathrm{~min}$. All tissue samples were run in duplicates.

Data analysis and statistics. The thresholds of the RT-qPCR analysis were set in the SDS2.1 software (Applied Biosystems). All quantitation cycle $(\mathrm{Cq})$-values with a s.d. $>0.3$ were excluded from further analysis; and if s.d. was $>0.3$ for one of the reference genes, the entire sample was excluded. $\Delta \mathrm{Cq}$-values were generated by normalising the Cq-values using the geometric mean of the reference genes. The tissue samples of the test cohort were sorted according to the median rank of the gene expression levels for the 15 genes included in the profile. The gene expression for each investigated gene was ranked under the assumption that a high expression was caused by hypoxia. Although Toustrup et al (2011) divided the patients into more hypoxic and less hypoxic groups based on the oxygen tension measurement, we have done this division according to the expression of the genes in the test cohort. Individual samples were classified by calculating the distance $(D)$ between the $\Delta \mathrm{Cq}$-values obtained in individual samples and the median $\Delta$ Cq-values of the test cohort in a manner similar to what was previously described by Toustrup et al (2011). Allocation into a more or a less hypoxic group was determined by the highest $\mathrm{B} / \mathrm{W}$ ratio in the test cohort. The $\mathrm{B} / \mathrm{W}$ ratio is defined as the variation between groups divided by the variation within a group. The cutpoints for the individual genes obtained in the test cohort were applied to the validation cohort to allocate patients into the more or the less hypoxic group, independent of the patient outcome.

The primary end point was disease-specific mortality, timed from the date of sarcoma diagnosis until death with sarcoma as death from other causes was regarded as a competing event. Secondary end points were as follows: overall mortality, timed from the date of sarcoma diagnosis until death from any cause, and development of metastatic disease, defined as metastasis with no possibility of curative treatment, timed from the date of primary sarcoma diagnosis until diagnosis of metastatic disease. The study ended on 15 April 2013. Patients alive at this date were censored. Differences in patients characteristics were tested using $\chi^{2}$-test, Fishers exact test, or Wilcoxon rank test. The cumulative incidence function was reported for disease-specific mortality or as overall mortality using the Fine and Gray model. Crude and adjusted estimates were reported with $95 \%$ confidence interval (CI) using the Cox proportional hazard model. The assumptions for the individual model were tested and no violations were observed. Adjustments were made for potential confounders affecting the association between the gene expression and the outcome. The confounders included were as follows: age at diagnosis (continuous), primary tumour size (continuous), comorbidity (yes $v s$ no), site (axial/pelvis/head $v s$ extremities), histological type (liposarcoma $v s$ UPS $v s$ synovial sarcoma $v s$ others), and surgical margin (wide $v s$ intralesional/marginal). The choice of potential confounders was based on literature review. In the multivariate analysis, 12 patients with grade 2 tumours, 6 patients with superficial tumours, and 4 patients who received chemotherapy were excluded. The model including the hypoxia-induced gene profile was tested against the model without the profile using likelihood-ratio test. The robustness of the final model including the hypoxia-induced gene profile was tested using the bootstrapping method with 1000 iterations.

Heat maps visualising the gene expression levels were generated by Genesis release 1.7.6 (Sturn et al, 2002) using the median centred data. The correlation between different tissue blocks from the same patient was tested by concordance correlation coefficient (Rho_c). A two-sided $P$ value $<0.05$ was regarded as significant. All statistical analyses were performed by using Stata version 14 (Metrika Consulting AB, Västervik, Sweden).

Ethics. The Ethics Committee of Denmark (no 1-10-72-233-12) and the Danish Agency of Data Protection (no 2012-41-0657) have approved the study.

\section{RESULTS}

Test and validation cohorts. Patient, tumour and treatment characteristics for the test, and validation cohorts are shown in Table 1 . There were statistically significant differences between the test and validation cohorts regarding the number of patients treated with postoperative radiation therapy, tumour grade, tumour depth, and margin after primary surgery.

The robustness of the gene expression in different tissue samples (different pathological blocks) from the same patient were tested in 15 patients. The strong correlation was manifested by a concordance correlation coefficient value of 0.88 (95\% CI: $0.85 ; 0.91)$. For the concordance of all the genes in the profile and each individual gene see Supplementary Document II (Supplementary Figure IIA and IIC). In 13 patients, the analysis of both tissue samples (blocks) lead to the same hypoxia classification, whereas in 2 patients, the classification was different between the blocks. For 16 patients, corresponding oxygen tension measurements and expression of the hypoxia-induced gene profile were present. A reverse association between the oxygen tension measurement and the gene expression was found as shown in Table 2. The Spearman's $\rho$ coefficient was indicating a weak correlation of $-0.45(P=0.04)$ between $\mathrm{pO}_{2}$ measurements and tumour size. The larger the tumour, the lower was the oxygen tension measurements (Supplementary Figure IIB).

Survival analysis. The expression of the genes expressions of the test cohort in the more and the less hypoxic tumours are illustrated in the heat maps (Figure 2A). Figure 2B shows the disease-specific mortality and Figure $2 \mathrm{C}$ the overall mortality in the test cohort for the more and the less hypoxic groups of patients. In the test cohort, the HR for patients with a high expression of the gene profile (the more hypoxic group) was 4.09 (95\% CI: 1.34; 12.46), $P=0.013$, compared with patients with a low expression of the gene profile regarding disease-specific mortality. The number of patients who experienced recurrent disease was higher in the more hypoxic, compared with the less hypoxic group; odds ratio of 3.96 (95\% CI: 0.98; 14.7), $P=0.03$.

Seventy-seven patients with localised grade 2 or 3 STS treated with surgical resection and postoperative radiation therapy (but no chemotherapy) were divided into a more hypoxic and a less hypoxic groups. The gene expression values used to set the cut-point of each gene in the test cohort were applied to the validation cohort. Of these 77 patients, $30(39 \%)$ were allocated to the more hypoxic group 
and 47 (61\%) were allocated to the less hypoxic group. Interestingly, all patients with synovial sarcoma were allocated to the less hypoxic group. Figure 2D shows the heat map of the gene expression in the validation cohort. Both the disease-specific mortality (Figure $2 \mathrm{E}$ ) and overall mortality (Figure $2 \mathrm{~F}$ ) were significantly higher in patients with more hypoxic tumours in the validation cohort. The HR was 2.03 (95\% CI: 1.02 ; 4.04) $P=0.045$ for disease-specific mortality and 2.01 (95\% CI: 1.11 ; 3.64) $P=0.02$ for overall mortality. In the validation cohort, 16 out of $30(53 \%)$ of patients in the more hypoxic group developed recurrent/metastatic disease compared with 23 out of 47 (49\%) of patients in the less hypoxic group.

Disease-specific mortality and overall mortality in the pooled data. Pooled analysis of the test and validation cohorts after exclusion of grade 2 tumours, superficial tumours, and patients treated with additional chemotherapy were done. The selection was done to eliminate confounding by grade and superficial location, as only a few patients had these characteristics. Patients, tumour, and treatment-related characteristics are shown in Table 3 . The results confirmed the prognostic value of the hypoxia-induced gene profile. Patients with high expression of the gene profile had significantly higher cumulative incidence of death from sarcoma compared with patients with low expression. The model including the hypoxia-induced gene profile was significantly better in a likelihood-ratio test $(P=0.0019)$ than the model without the hypoxia-induced gene profile. Both univariate and multivariate analyses were performed and are shown in Table 4 . The adjusted HR for the development of metastatic disease was $2.61(1.27 ; 5.33)$ $P=0.009$ for patients with more hypoxic tumours compared with the less hypoxic tumours. Using bootstrapping, the HR was 3.18 (95\% CI: 1.0 ; 9.8) $P=0.044$.

\section{DISCUSSION}

The hypoxia-induced gene profile investigated in this paper was developed in head and neck cancer (Toustrup et al, 2012), but

Table 2. Distribution of patients with both oxygen tension measurements and gene expression analysis $(n=16)$

\begin{tabular}{|l|c|c|}
\cline { 2 - 3 } & \multicolumn{2}{c|}{ Oxygen tension measurements } \\
\hline Gene expression & $\mathbf{p O}_{\mathbf{2}}<\mathbf{1 9} \mathbf{~} \mathbf{m ~ H g}$ & $\mathbf{p O}_{\mathbf{2}}>\mathbf{1 9} \mathbf{~ m m ~ H g}$ \\
\hline High (more hypoxic) & 2 & 9 \\
\hline Low (less hypoxic) & 4 & 1 \\
\hline Fisher's exact test $=0.036$. & \\
\hline
\end{tabular}

Table 1. Patient, tumour, and treatment characteristics of patient treated for high-grade localised soft tissue sarcoma ( $n=132$ )




A

Test cohort

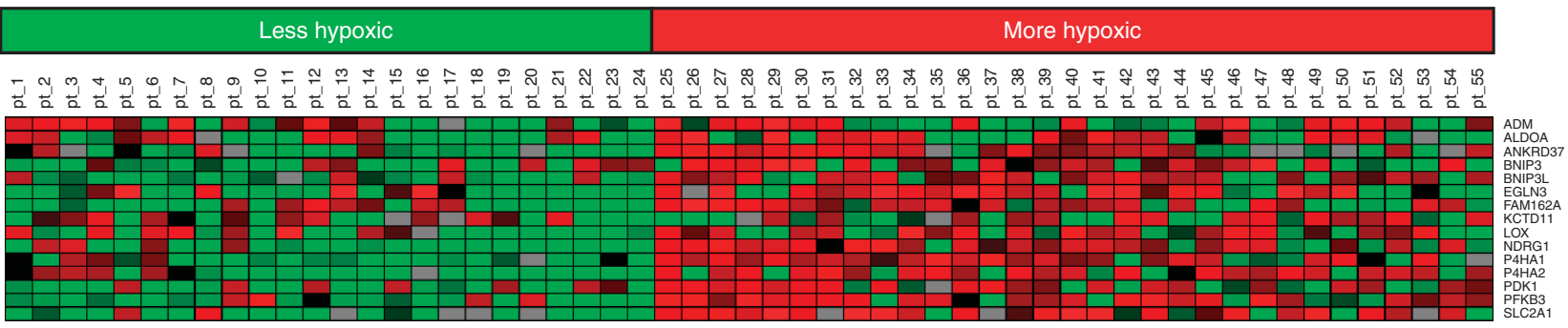

B

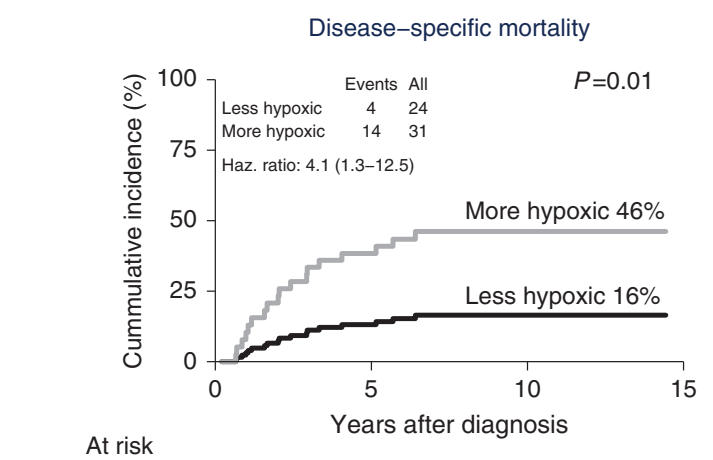

Less hypoxic 24

More hypoxic 31

$20 \quad 7 \quad 3$

C

Overall mortality

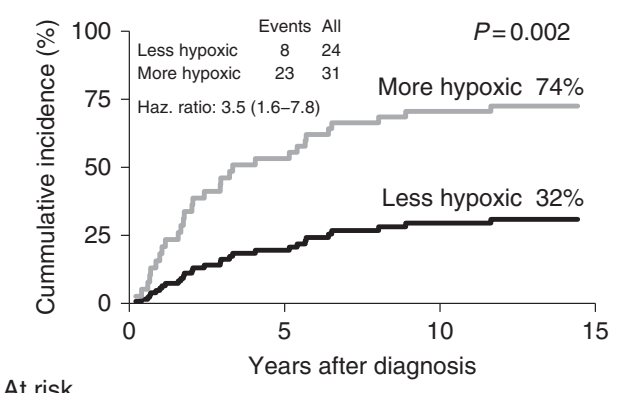

Less hypoxic $24 \quad 20 \quad 7 \quad 3$

$\begin{array}{llll}\text { More hypoxic } & 31 & 13 & 6\end{array}$

D



$\mathbf{E}$



$\mathbf{F}$

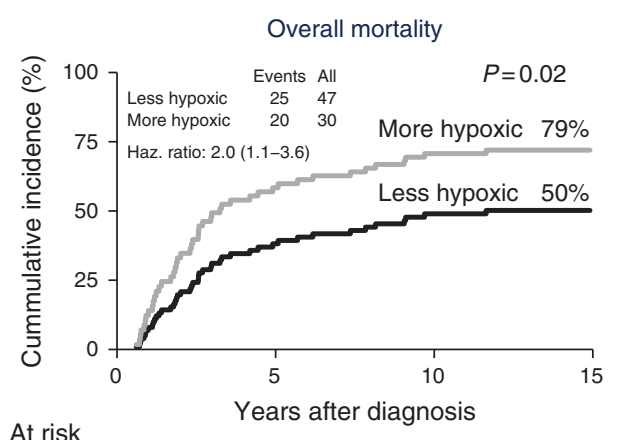

Less hypoxic 47

More hypoxic 30
30

9
9

2

Figure 2. Disease-specific and overall mortality for the test and validation cohort. (A) Heat map visualising gene expression in the test cohort of 55 STS tissue samples (1-55), red is upregulated genes, green is downregulated genes, and grey is missing values (expression levels below the detection threshold). All gene expression levels are median centred. (B) Disease-specific mortality in the test cohort. (C) Overall mortality in test cohort. Less hypoxic: patients allocated to the less hypoxic group with low expression of the hypoxia-induced genes. More hypoxic: patients allocated to the more hypoxic group with high gene expression of the hypoxia-induced genes. The values are unadjusted and based on Fine and Gray competing risk model. (D) Heat map visualising gene expression from the validation cohort of 77 STS tissue samples (1-77). (E) Diseasespecific mortality in the validation cohort. (F) Overall mortality in the validation cohort.

recent in vitro data have demonstrated a potential in other cancer types (Sorensen et al, 2015). This study demonstrated that the expression of the hypoxia-induced gene profile tested in pretreatment FFPE tissue is a prognostic factor for STS patients.

The unique composition of genes presented here takes into account different mechanisms by which hypoxia affects tumour biology and the collective effect of these genes has not been described in sarcomas before. The hypoxia-induced gene profile includes genes such as LOX, P4HA1, and P4HA2 that are involved in extracellular matrix modulation, a mechanism affected by hypoxia. The modulation of the extracellular matrix is important to facilitate tumour cell migration and enhances sarcoma metastasis as shown by Eisinger-Mathason et al (2013). 
Table 3. Patient, tumour, and treatment characteristics of the pooled STS patients with localised high-grad soft tissue sarcoma $(n=110)$

\begin{tabular}{|c|c|c|c|c|}
\hline & Total & More hypoxic & Less hypoxic & $P$-value ${ }^{a}$ \\
\hline Total & & 55 & 55 & \\
\hline $\begin{array}{l}\text { Age at diagnosis (years) } \\
\text { Median (range) }\end{array}$ & 61 (24-83) & 64 (36-83) & 54 (24-81) & $<0.01$ \\
\hline $\begin{array}{l}\text { Sex } \\
\text { Female } \\
\text { Male }\end{array}$ & $\begin{array}{l}42(38) \\
68(62)\end{array}$ & $\begin{array}{l}18(33) \\
37(67)\end{array}$ & $\begin{array}{l}24(44) \\
31(56)\end{array}$ & 0.24 \\
\hline $\begin{array}{l}\text { Comorbidity } \\
\text { No } \\
\text { Yes }\end{array}$ & $\begin{array}{l}87(79) \\
23(21)\end{array}$ & $\begin{array}{l}41(75) \\
14(25)\end{array}$ & $\begin{array}{l}46(84) \\
9(16)\end{array}$ & 0.35 \\
\hline $\begin{array}{l}\text { Tumour size }(\mathrm{cm}) \\
\text { Median (range) }\end{array}$ & $9(2-26)$ & $10(2-26)$ & $9(2-20)$ & 0.25 \\
\hline $\begin{array}{l}\text { Site } \\
\text { Axial/pelvis } \\
\text { Extremities }\end{array}$ & $\begin{array}{l}12(11) \\
98(89)\end{array}$ & $\begin{array}{l}6(11) \\
49(89)\end{array}$ & $\begin{array}{l}6(11) \\
49(89)\end{array}$ & 1 \\
\hline $\begin{array}{l}\text { Margin } \\
\text { Wide } \\
\text { Intralesional/marginal }\end{array}$ & $\begin{array}{l}62(56) \\
48(44)\end{array}$ & $\begin{array}{l}28(51) \\
27(49)\end{array}$ & $\begin{array}{l}34(62) \\
21(38)\end{array}$ & 0.25 \\
\hline $\begin{array}{l}\text { Radiation } \\
\text { Yes } \\
\text { No }\end{array}$ & $\begin{array}{l}93(85) \\
17(15)\end{array}$ & $\begin{array}{l}44(80) \\
11(20)\end{array}$ & $\begin{array}{l}49(89) \\
6(11)\end{array}$ & 0.29 \\
\hline $\begin{array}{l}\text { Develops metastasis } \\
\text { Yes } \\
\text { No }\end{array}$ & $\begin{array}{l}55(50) \\
55(50)\end{array}$ & $\begin{array}{l}30(55) \\
25(45)\end{array}$ & $\begin{array}{l}25(45) \\
30(55)\end{array}$ & 0.34 \\
\hline
\end{tabular}

Our findings showing an upregulation of genes encoding proteins involved in the glycolysis, such as SLC2A1, PFKB3, ALDOA, and PDK1, could be explained by the metabolic switch from oxidative phosphorylation to glycolysis as a result of tumour cell hypoxia (Payen et al, 2015). However, it is important to remember that these genes could also be upregulated in cancers for reasons unrelated to hypoxia. The prognostic impact of these glycolysis genes are in concordance with the data showing that the total tumour glycolysis estimated by FDG PET/ CT in sarcoma patients is associated with metastatic disease (Choi et al, 2013).

All the genes included in the profile are involved in the mechanisms that facilitate aggressive tumour behaviour such as metastasis and/or resistance to treatment (Erler et al, 2009; Cairns et al, 2011; Gilkes et al, 2014; Tung et al, 2015). Therefore, this gene profile may be a generally applicable signature for hypoxic and/or aggressive tumours.

To the best of the authors' knowledge, this is the second largest study of a prognostic gene profile in STS patients after the CINSARC profile (Chibon et al, 2010). Yet, because of the various histological subtypes, the number of patients in each histological subtype is still relatively small. This hinders any pathology-specific analysis of data.

The relative wide 95\% CIs of the survival estimate means these are subject to some uncertainty. Furthermore, the lower HR for hypoxia in the validation cohort indicates a weaker relationship between DFS and the hypoxic gene signature, and confirms the importance of further validation of this gene signature in an independent cohort. This, however, does not affect the fact that the differences in disease-specific mortality, overall mortality, and development of metastasis were significant.
The development of metastasis was the secondary end point used in this study. This end point was defined as metastasis with no possibility of curative treatment. Specifying the palliative intent in the definition of the end point was based on the assumption that tumours that develop solitary or oligometastasis that could be treated curatively may have a different and less aggressive biology compared with tumours that develop widespread systemic disease.

Intra-tumour heterogeneity is a well-known issue in regards to the extent of hypoxia (Horsman et al, 2012), and this is a concern for biomarker studies based on single tumour biopsies. For the hypoxia signature, this question has been raised in a previous study (Toustrup et al, 2016), where intra-tumour heterogeneity was tested in multiple biopsies with different tumour tissue content from individual head and neck cancer patients. It was found that for the majority of patients, all biopsies from the same patient were classified the same. The conclusion from this study was, that if multiple biopsies are available, the optimal biopsy is selected by taking the relative content of invasive carcinoma, minimal necrosis, and the total size of the tumour biopsy into account. We have in this study performed a similar validation as described in Material and Methods and most patients were classified in the same groups used two different tissue samples.

A major strength of the present study is that the cut-point ( $\Delta$ Cq-value) determined by the test cohort for each gene was applied to the validation cohort independent of the patient's outcome. The data shown by Sorensen et al indicated that this hypoxia-induced gene profile may be universal for cancer, whereas our data indicated that different cancers may have different cut-points for each gene as the cut-points found in this study were indeed different from those found by Toustrup et al. This study 
Table 4. Multivariate analysis pooling the test cohort and validation cohort

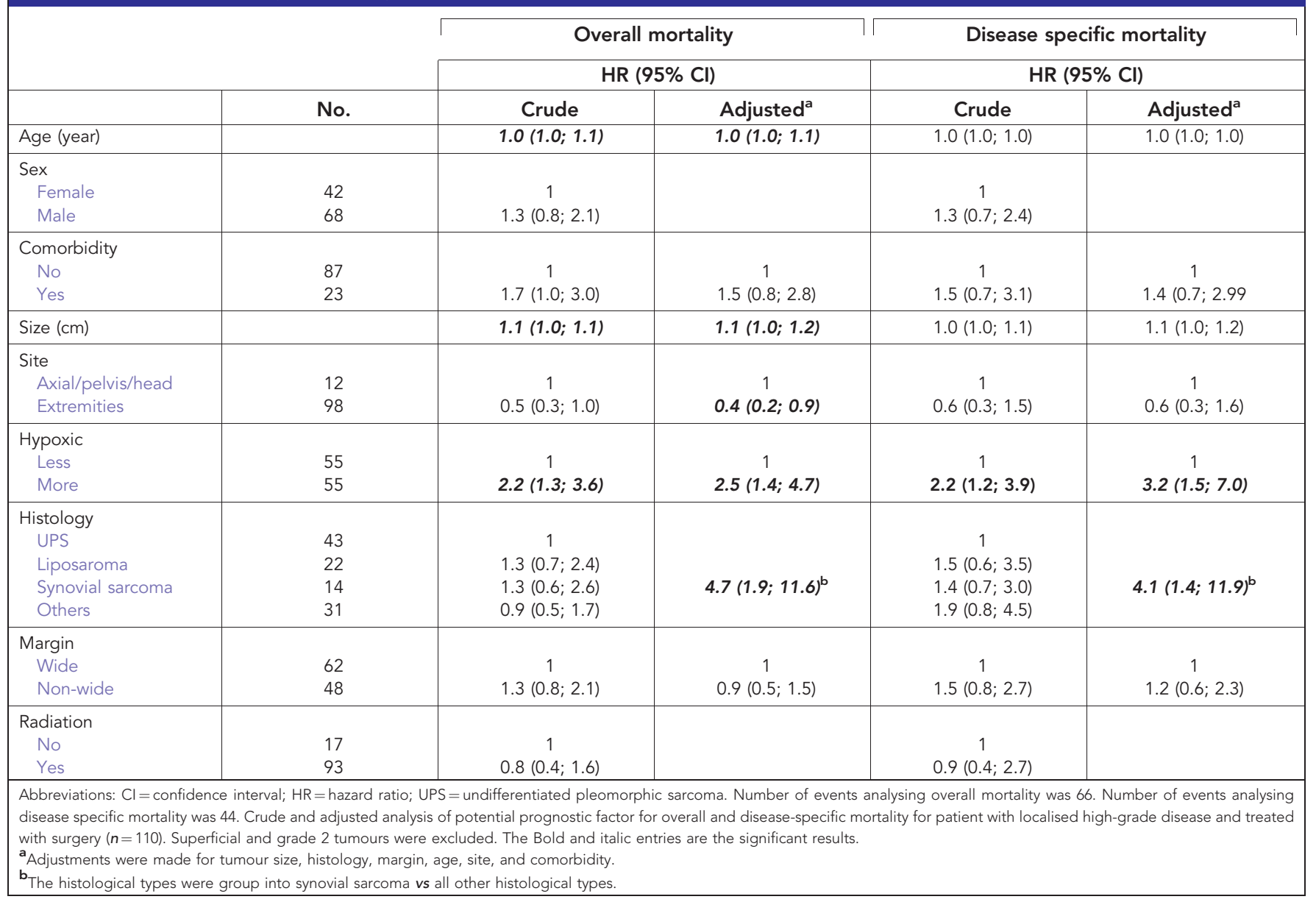

also suggests that even various histological types of sarcomas may have different cut-points.

Other points of strength in this study are as follows: the strong correlation between tissue samples taken from the same patient, who testified for the robustness of the data, and the significant association between disease-specific survival and the hypoxiainduced gene profile, shown by using the bootstrapping method on the pooled data.

Data for this study were collected from a comprehensive newly validated sarcoma database covering all sarcoma patients in a welldefined geographic part of Denmark (Maretty-Nielsen et al, 2013). In the present study, we adjusted for confounders, which are known to affect overall survival of STS; even so, we observed a highly significant association between the hypoxia-induced gene profile and disease-specific mortality. Another important point is that the proposed analysis using FFPE tissue samples to evaluate the expression level of the hypoxia-induced gene profile can be used in clinical practice.

In the present study, there was no association between the hypoxia-induced gene expression and the Eppendorf oxygen tension measurements in a small group of 16 patients with high-grade sarcoma. This could simply be owing to the small number of patients with data available on tumour oxygen tension status.

Another possible explanation could be that $\mathrm{pO}_{2}$ measurements with the Eppendorf method could have been affected by, for example, tumour size or the degree of necrosis within a tumour. Previous clinical data in STS showed no such association, neither between tumour $\mathrm{pO}_{2}$ or tumour necrosis or size, respectively
(Nordsmark et al, 1996). Preclinical studies using mouse models have collectively shown that the larger the tumour, the higher was the degree of necrosis and the lower was the oxygen tension inside the tumour (Vaupel et al, 1989; Khalil et al, 1995; Milross et al, 1997).

In this study, only a week correlation between tumour size and oxygen tension measurements was observed (Supplementary Figure IIB). This weak correlation can therefore cast a shadow of doubt on whether these genes in sarcomas are driven by hypoxia directly and not by other hypoxia-independent signalling pathways.

Indeed, our results cannot answer the question of whether these genes in sarcomas are driven by hypoxia or by other signalling pathways that are totally or partly independent of hypoxia. The distinction is important for understanding the underlying mechanism and determining the predictive value of this profile. As the current study was not designed to make this distinction, this point will be investigated in future studies testing the predictive role of this profile in determining the response to anti-hypoxic drugs alone or in combination with chemotherapy.

Determining tumour hypoxia using panel of genes, referred to as Hypoxia Gene Expression Signatures is now a commonly used strategy (Toustrup et al, 2012; Harris et al, 2015; Pettersen et al, 2015) This is due to the advantages of using a cumulated gene response to hypoxia, instead of focusing on a single biomarker. Previously, immunohistochemistry (IHC) using single markers has been used in number of clinical studies, but because of the number of disadvantages of this method (Harris et al, 2015) it was not used 
here. It was also felt treat the use of IHC would not add more information to the results particularly that the correlation between the expression of the hypoxia inducible genes included in the 15-gene hypoxia-induced gene profile and tumour hypoxia has been validated in a preclinical study, with tumour hypoxia being assessed by FAZA, an exogenous hypoxia marker (Toustrup et al, 2011).

In conclusion, the results of the present paper suggest a new hypoxia-induce gene profile prognostic for STS patients.

\section{ACKNOWLEDGEMENTS}

We appreciate the efforts and technical assistance of A. Baden, M. Johannesen, N. Hansen, and C. Wulff-Høyer. The A.P. Møller and Christine McKinney Møller Foundation, EC FP7 project METOXIA (project no. 222741) and the faculty of Aarhus University have supported this research. The study was supported by a fellowship from Aarhus University, the A.P. Møller, and Christine McKinney Møller Foundation and EC FP7 project METOXIA (project no. 222741).

\section{CONFLICT OF INTEREST}

The authors declare no conflict of interest.

\section{AUTHOR CONTRIBUTIONS}

Conception and design: all authors. Development of methodology: Kasper Toustrup, Jens Overgaard, Marianne Nordsmark, Brita Singers Sørensen, Jan Alsner, Ninna Aggerholm-Pedersen. Acquisition of the data: Steen Baerentzen, Ole Steen Nielsen, Katja Maretty-Kongsgaard, Marianne Nordsmark, Brita Singers Sørensen, Jan Alsner, Akmal Safwat, Ninna Aggerholm-Pedersen. Analysis and interpretation of thr data: all authors. Writing the article: Ninna Aggerholm-Pedersen. Review and/or revision of the manuscript: all authors. Study supervision: Akmal Safwat, Jens Overgaard, Jan Alsner, Marianne Nordsmark, Ole Steen Nielsen.

\section{REFERENCES}

Aggerholm-Pedersen N, Safwat A, Baerentzen S, Nordsmark M, Nielsen OS, Alsner J, Sorensen BS (2014) The importance of reference gene analysis of formalin-fixed, paraffin-embedded samples from sarcoma patients-an often underestimated problem. Transl Oncol 7: 687-693.

Bentzen L, Keiding S, Nordsmark M, Falborg L, Hansen SB, Keller J, Nielsen OS, Overgaard J (2003) Tumour oxygenation assessed by 18F-fluoromisonidazole PET and polarographic needle electrodes in human soft tissue tumours. Radiother Oncol 67: 339-344.

Bohmann K, Hennig G, Rogel U, Poremba C, Mueller BM, Fritz P, Stoerkel S, Schaefer KL (2009) RNA extraction from archival formalin-fixed paraffinembedded tissue: a comparison of manual, semiautomated, and fully automated purification methods. Clin Chem 55: 1719-1727.

Brizel DM, Scully SP, Harrelson JM, Layfield LJ, Bean JM, Prosnitz LR, Dewhirst MW (1996) Tumor oxygenation predicts for the likelihood of distant metastases in human soft tissue sarcoma. Cancer Res 56: 941-943.

Busk M, Horsman MR (2013) Relevance of hypoxia in radiation oncology: pathophysiology, tumor biology and implications for treatment. Q J Nucl Med Mol Imaging 57: 219-234.

Cairns RA, Harris IS, Mak TW (2011) Regulation of cancer cell metabolism. Nat Rev Cancer 11: 85-95.

Chibon F, Lagarde P, Salas S, Perot G, Brouste V, Tirode F, Lucchesi C, de Reynies A, Kauffmann A, Bui B, Terrier P, Bonvalot S, Le Cesne A,
Vince-Ranchere D, Blay JY, Collin F, Guillou L, Leroux A, Coindre JM, Aurias A (2010) Validated prediction of clinical outcome in sarcomas and multiple types of cancer on the basis of a gene expression signature related to genome complexity. Nat Med 16: 781-787.

Choi ES, Ha SG, Kim HS, Ha JH, Paeng JC, Han I (2013) Total lesion glycolysis by $18 \mathrm{~F}-\mathrm{FDG} \mathrm{PET} / \mathrm{CT}$ is a reliable predictor of prognosis in soft-tissue sarcoma. Eur J Nucl Med Mol Imaging 40: 1836-1842.

Eisinger-Mathason TS, Zhang M, Qiu Q, Skuli N, Nakazawa MS, Karakasheva T, Mucaj V, Shay JE, Stangenberg L, Sadri N, Pure E, Yoon SS, Kirsch DG, Simon MC (2013) Hypoxia-dependent modification of collagen networks promotes sarcoma metastasis. Cancer Discov 3: 1190-1205.

El-Naggar AM, Veinotte CJ, Cheng H, Grunewald TG, Negri GL, Somasekharan SP, Corkery DP, Tirode F, Mathers J, Khan D, Kyle AH, Baker JH, LePard NE, McKinney S, Hajee S, Bosiljcic M, Leprivier G, Tognon CE, Minchinton AI, Bennewith KL, Delattre O, Wang Y, Dellaire G, Berman JN, Sorensen PH (2015) Translational activation of HIFlalpha by YB-1 promotes sarcoma metastasis. Cancer Cell 27: 682-697.

Erler JT, Bennewith KL, Cox TR, Lang G, Bird D, Koong A, Le QT, Giaccia AJ (2009) Hypoxia-induced lysyl oxidase is a critical mediator of bone marrow cell recruitment to form the premetastatic niche. Cancer Cell 15: 35-44.

Evans SM, Hahn SM, Magarelli DP, Zhang PJ, Jenkins WT, Fraker DL, Hsi RA, McKenna WG, Koch CJ (2001) Hypoxia in human intraperitoneal and extremity sarcomas. Int J Radiat Oncol Biol Phys 49: 587-596.

Evans SM, Koch CJ (2003) Prognostic significance of tumor oxygenation in humans. Cancer Lett 195: 1-16.

Gilkes DM, Semenza GL, Wirtz D (2014) Hypoxia and the extracellular matrix: drivers of tumour metastasis. Nat Rev Cancer 14: 430-439.

Harris BH, Barberis A, West CM, Buffa FM (2015) Gene expression signatures as biomarkers of tumour hypoxia. Clin Oncol ( $R$ Coll Radiol) 27: 547-560.

Hockel M, Schlenger K, Aral B, Mitze M, Schaffer U, Vaupel P (1996) Association between tumor hypoxia and malignant progression in advanced cancer of the uterine cervix. Cancer Res 56: 4509-4515.

Horsman MR, Mortensen LS, Petersen JB, Busk M, Overgaard J (2012) Imaging hypoxia to improve radiotherapy outcome. Nat Rev Clin Oncol 9: 674-687.

Hunter FW, Wouters BG, Wilson WR (2016) Hypoxia-activated prodrugs: paths forward in the era of personalised medicine. Br J Cancer 114: 1071-1077.

Khalil AA, Horsman MR, Overgaard J (1995) The importance of determining necrotic fraction when studying the effect of tumour volume on tissue oxygenation. Acta Oncol 34: 297-300.

Kim JI, Choi KU, Lee IS, Choi YJ, Kim WT, Shin DH, Kim K, Lee JH, Kim JY, Sol MY (2015) Expression of hypoxic markers and their prognostic significance in soft tissue sarcoma. Oncol Lett 9: 1699-1706.

Kim YJ, Lee HJ, Kim TM, Eisinger-Mathason TS, Zhang AY, Schmidt B, Karl DL, Nakazawa MS, Park PJ, Simon MC, Yoon SS (2013) Overcoming evasive resistance from vascular endothelial growth factor a inhibition in sarcomas by genetic or pharmacologic targeting of hypoxia-inducible factor 1alpha. Int J Cancer 132: 29-41.

Maretty-Nielsen K, Aggerholm-Pedersen N, Keller J, Safwat A, Baerentzen S, Pedersen AB (2013) Population-based Aarhus Sarcoma Registry: validity, completeness of registration, and incidence of bone and soft tissue sarcomas in western Denmark. Clin Epidemiol 5: 45-56.

Maretty-Nielsen K, Aggerholm-Pedersen N, Safwat A, Jorgensen PH, Hansen BH, Baerentzen S, Pedersen AB, Keller J (2014) Prognostic factors for local recurrence and mortality in adult soft tissue sarcoma of the extremities and trunk wall. Acta Orthop 85: 323-332.

Milross CG, Tucker SL, Mason KA, Hunter NR, Peters LJ, Milas L (1997) The effect of tumour size on necrosis and polarographically measured pO2. Acta Oncol 36: 183-189.

Nordsmark M, Alsner J, Keller J, Nielsen OS, Jensen OM, Horsman MR, Overgaard J (2001) Hypoxia in human soft tissue sarcomas: adverse impact on survival and no association with p53 mutations. Br J Cancer 84 1070-1075.

Nordsmark M, Bentzen SM, Rudat V, Brizel D, Lartigau E, Stadler P, Becker A, Adam M, Molls M, Dunst J, Terris DJ, Overgaard J (2005) Prognostic value of tumor oxygenation in 397 head and neck tumors after 
primary radiation therapy. An international multi-center study. Radiother Oncol 77: 18-24.

Nordsmark M, Hoyer M, Keller J, Nielsen OS, Jensen OM, Overgaard J (1996) The relationship between tumor oxygenation and cell proliferation in human soft tissue sarcomas. Int J Radiat Oncol Biol Phys 35: 701-708.

Payen VL, Brisson L, Dewhirst MW, Sonveaux P (2015) Common responses of tumors and wounds to hypoxia. Cancer J 21: 75-87.

Pettersen EO, Ebbesen P, Gieling RG, Williams KJ, Dubois L, Lambin P, Ward C, Meehan J, Kunkler IH, Langdon SP, Ree AH, Flatmark K, Lyng H, Calzada MJ, Peso LD, Landazuri MO, Gorlach A, Flamm H, Kieninger J, Urban G, Weltin A, Singleton DC, Haider S, Buffa FM, Harris AL, Scozzafava A, Supuran CT, Moser I, Jobst G, Busk M, Toustrup K, Overgaard J, Alsner J, Pouyssegur J, Chiche J, Mazure N, Marchiq I, Parks S, Ahmed A, Ashcroft M, Pastorekova S, Cao Y, Rouschop KM, Wouters BG, Koritzinsky M, Mujcic H, Cojocari D (2015) Targeting tumour hypoxia to prevent cancer metastasis. From biology, biosensing and technology to drug development: the METOXIA consortium. J Enzyme Inhib Med Chem 30: 689-721.

Soes S, Sorensen BS, Alsner J, Overgaard J, Hager H, Hansen LL, Kristensen LS (2013) Identification of accurate reference genes for RT-qPCR analysis of formalin-fixed paraffin-embedded tissue from primary non-small cell lung cancers and brain and lymph node metastases. Lung Cancer 81: 180-186.

Sorensen BS, Knudsen A, Wittrup CF, Nielsen S, Aggerholm-Pedersen N, Busk M, Horsman M, Hoyer M, Bouchelouche PN, Overgaard J, Alsner J (2015) The usability of a 15-gene hypoxia classifier as a universal hypoxia profile in various cancer cell types. Radiother Oncol 116: $346-351$.
Sorensen BS, Toustrup K, Horsman MR, Overgaard J, Alsner J (2010) Identifying $\mathrm{pH}$ independent hypoxia induced genes in human squamous cell carcinomas in vitro. Acta Oncol 49: 895-905.

Sturn A, Quackenbush J, Trajanoski Z (2002) Genesis: Cluster analysis of microarray data. Bioinformatics 18(1): 207-208.

Toustrup K, Sorensen BS, Lassen P, Wiuf C, Alsner J, Overgaard J. Danish Head and Neck Cancer Group (DAHANCA) (2012) Gene expression classifier predicts for hypoxic modification of radiotherapy with nimorazole in squamous cell carcinomas of the head and neck. Radiother Oncol 102: 122-129.

Toustrup K, Sorensen BS, Metwally MA, Tramm T, Mortensen LS, Overgaard J, Alsner J (2016) Validation of a 15-gene hypoxia classifier in head and neck cancer for prospective use in clinical trials. Acta Oncol; e-pub ahead of print 10 May 2016.

Toustrup K, Sorensen BS, Nordsmark M, Busk M, Wiuf C, Alsner J, Overgaard J (2011) Development of a hypoxia gene expression classifier with predictive impact for hypoxic modification of radiotherapy in head and neck cancer. Cancer Res 71: 5923-5931.

Tung JC, Barnes JM, Desai SR, Sistrunk C, Conklin MW, Schedin P, Eliceiri KW, Keely PJ, Seewaldt VL, Weaver VM (2015) Tumor mechanics and metabolic dysfunction. Free Radic Biol Med 79: 269-280.

Vaupel P, Okunieff P, Kallinowski F, Neuringer LJ (1989) Correlations between 31P-NMR spectroscopy and tissue $\mathrm{O} 2$ tension measurements in a murine fibrosarcoma. Radiat Res 120: 477-493.

This work is published under the standard license to publish agreement. After 12 months the work will become freely available and the license terms will switch to a Creative Commons AttributionNonCommercial-Share Alike 4.0 Unported License.

Supplementary Information accompanies this paper on British Journal of Cancer website (http://www.nature.com/bjc) 